\title{
Girl-Centered Program Design in Indian Country
}

Kelly Hallman

Population Council

Stephanie Martinez

Follow this and additional works at: https://knowledgecommons.popcouncil.org/departments_sbsr-pgy How does access to this work benefit you? Let us know!

\section{Recommended Citation}

Hallman, Kelly and Stephanie Martinez. 2018. "Girl-Centered Program Design in Indian Country," IMAGEN Brief no. 4. New York: Indigenous Adolescent Girls' Empowerment Network (IMAGEN). 
NORTH IDEAL NOSECuRTY

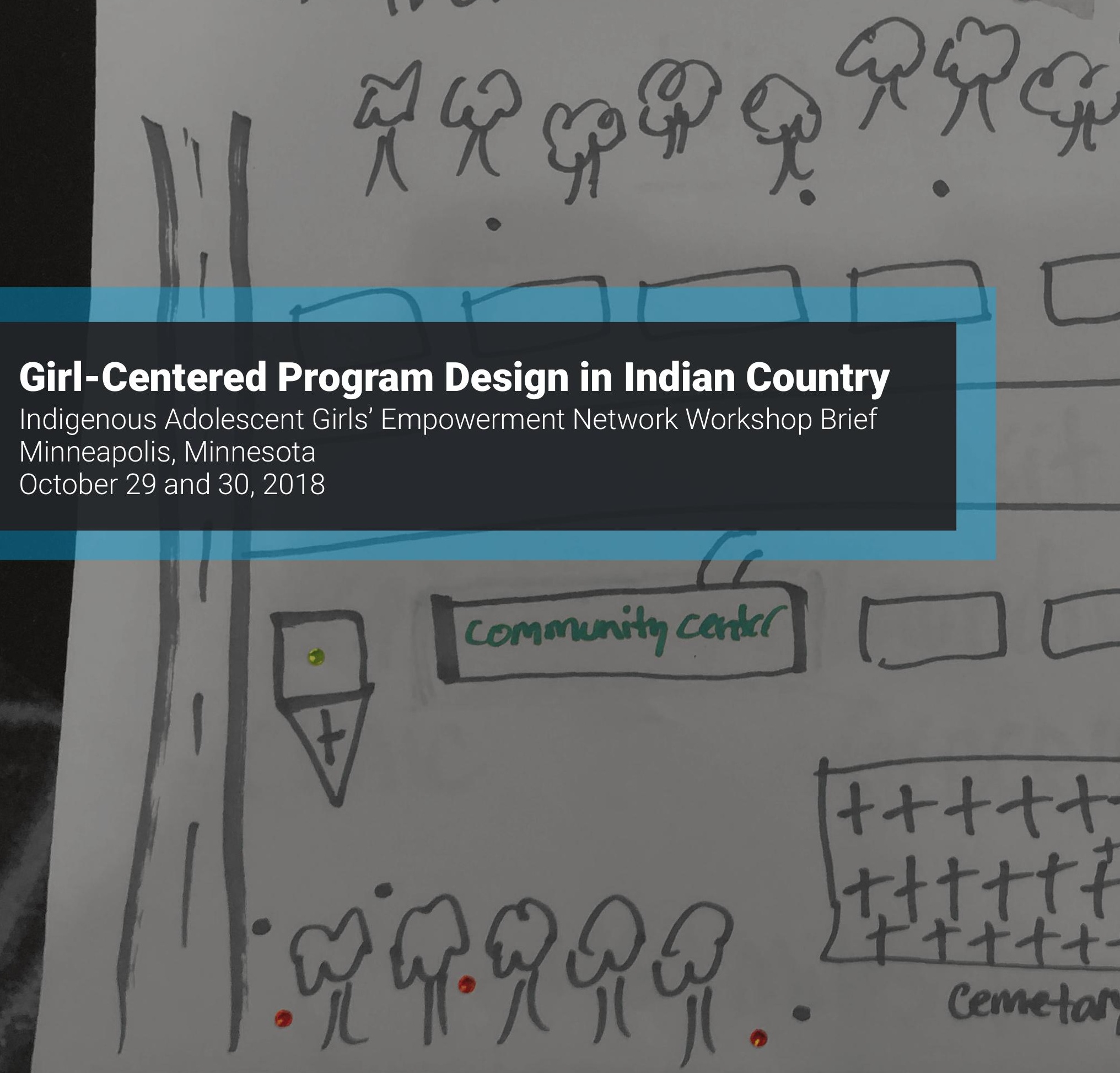




\section{A NETWORK BUILT FOR INDIGENOUS GIRLS}

On October 29 and 30, 2018, representatives from 13 tribal communities and organizations came together for "Girl-Centered Program Design in Indian Country," a workshop on strategizing ways to meet the critical needs of indigenous adolescent girls in the U.S. Hosted by the Indigenous Adolescent Girls' Empowerment Network

(IMAGEN) in Minneapolis, a city itself home to a diverse American Indian community and built on the lands of the Dakota and Ojibwe, the 2-day event

brought together veteran network members, subject matter experts, and prospective organizations to exchange experiences, ideas, and tools for supporting the hardest-to-reach girls in Indian Country.

Over the course of more than 15 sessions covering girl-centered program

design from theory to application, participants were encouraged to engage with the tools and case studies in order to begin to imagine a model that could work in their own community's context.
Examples of the interactive workshop sessions included:

$>$ Systematic steps to reach the girls most often missed by youth-oriented interventions

$>$ Building girls' protective assets by age segment

$>$ Assessing resources and risks within the accessible communities of girls

$>$ Global evidence from girl-centered programs

$>$ Incorporating science, technology, engineering, and math content

$>$ Incorporating social and emotional skills content

$>$ Introducing trauma-reducing technologies and approaches through girl spaces

$>$ The importance of mentors and their roles in successful girl programs

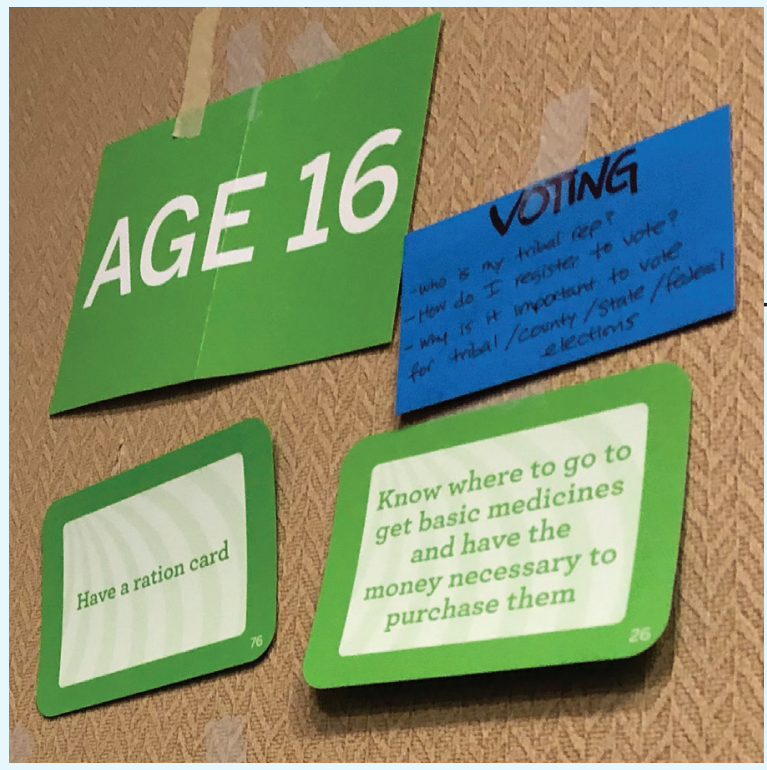

In one activity designed to identify assets needed by a minimum age, workshop participants decided that understanding the importance of tribal voting and representation was an asset American Indian girls must possess by age 16 . 


\section{LEARNING TOGETHER, BUILDING STRONGER}

Throughout the workshop, participants engaged in discussions about the obstacles faced by local indigenous

girls, both on and off reservations, as they navigate the road from childhood to adulthood, facing sexual objectification, shrinking physical and social spaces, and experiences of social processes that are often traumatic and unseen. Participants

noted with great concern the potential negative influence that powerful new forces such as social media imposed upon the lives of adolescent girls in the midst of building their identities,

compounded dangerously by the longstanding historical legacy of racism and forced shame in embracing an indigenous identity.

However, participants also identified the unique strengths of adolescent and American Indian girls, and the opportunities that existed to support them in navigating this risky and formative period of life. For example, girls are regularly characterized as

being financial "savers," are often defined by their resilience, and within many indigenous communities, are descendants of powerful matrilineal traditions.
In providing more local examples, LeToy Lunderman from the White Buffalo Calf

Women's Society (WBCWS), the first organization to pilot a program with IMAGEN, discussed how her team created a curriculum for its Wicincila Society mentorship program built specifically to address the indigenous girl experience within a framework that honored and incorporated Lakota tradition.

Dr. Kathy DeerlnWater, on behalf of the American Indian Science and Engineering Society (AISES), shared the powerful case for promoting STEM initiatives in the young indigenous community as a longterm strategy for building a new generation of previously untapped indigenous STEM leadership. Dr. DeerInWater also discussed the unique opportunities that existed in presenting STEM education synchronously with longstanding indigenous knowledge and practices.

Women Win, a global organization that promotes girls' and women's empowerment through sports, further discussed the ways in which physical activities could be mobilized within indigenous girl programming to build confidence, develop critical life skills, create social bonds, secure community attention, and reinforce ties to ancestral sport traditions.

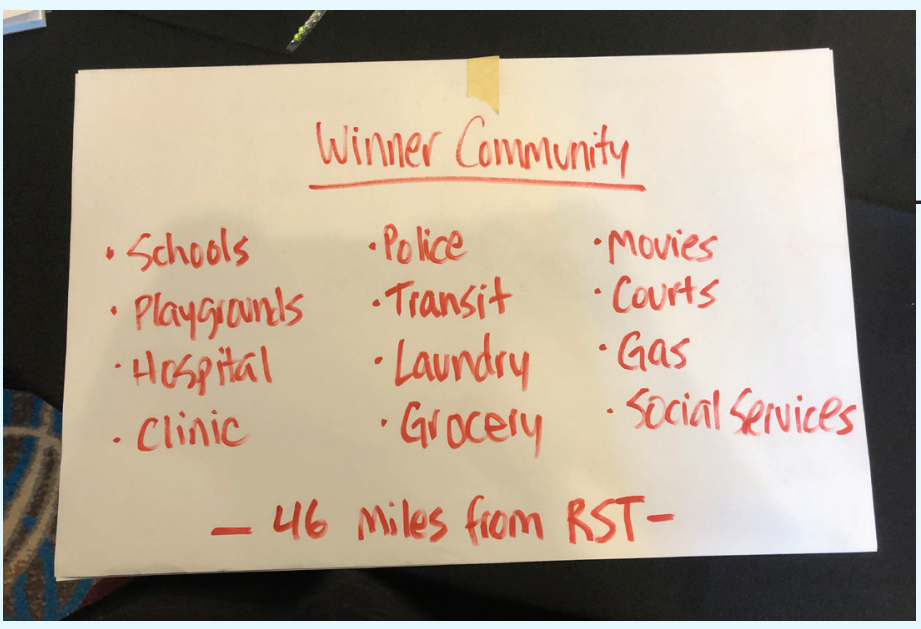

uring a session on the importance of understanding physical and social landscapes, participants identified the specific sites and services adolescent girls were able to access. 


\section{MOVEMENT BUILDING}

The workshop was also honored by the attendance of Minnesota State Senator

Patricia Torres Ray and Minnesota State

Representative Mary Kunesh-Podein, who shared their remarks on Day 1.

The two state leaders discussed promising trends in the emergence of candidates running for office from

diverse backgrounds, the power that comes from having previously underrepresented indigenous voices in halls of power, as well as current initiatives taking place to investigate critical issues such as the murdered and missing indigenous women crisis in Minnesota.

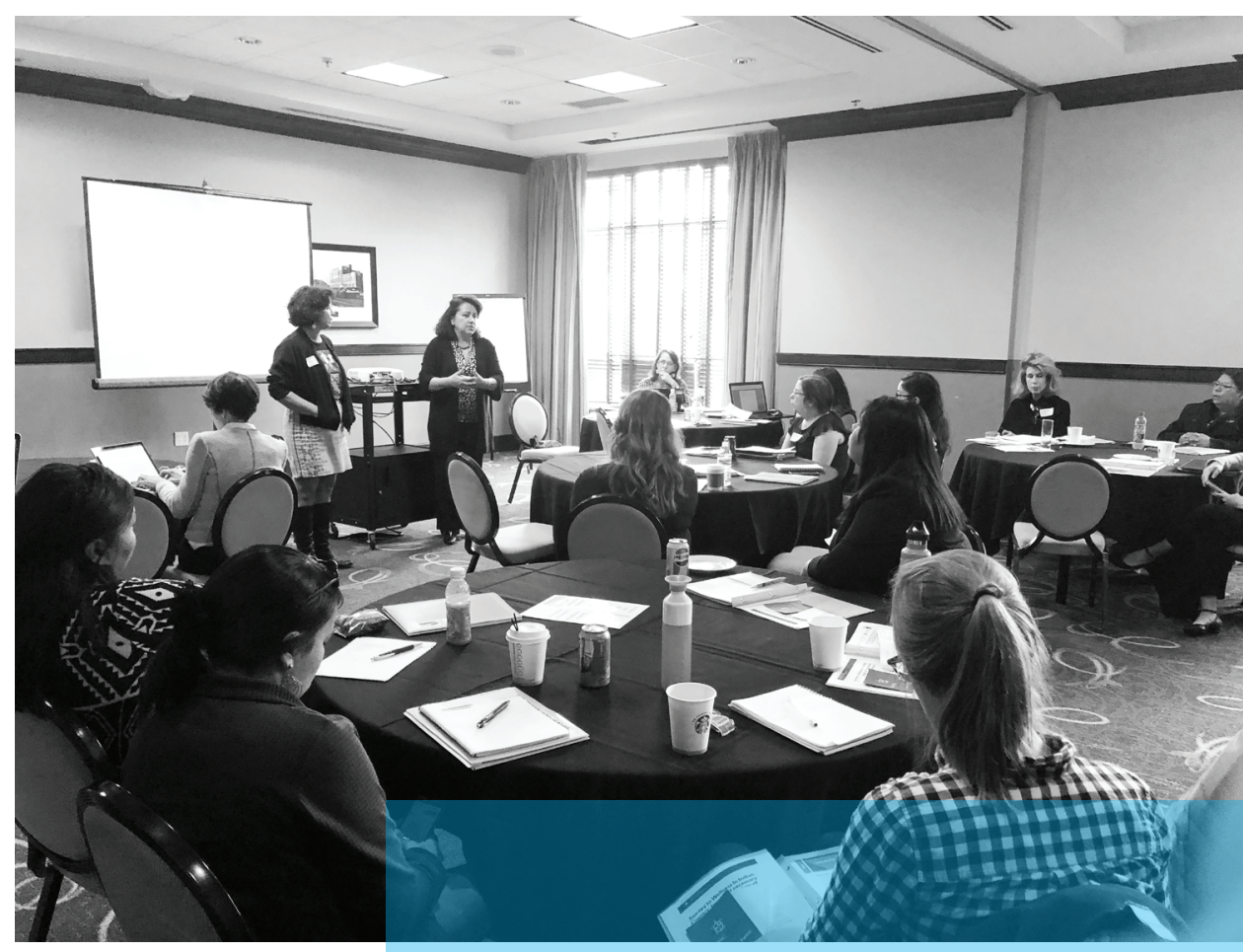

Minnesota State Congresswomen Patricia Torres Ray and Mary KuneshPodein address workshop participants

Participants commemorate the end of IMAGEN's workshop in Minneapolis

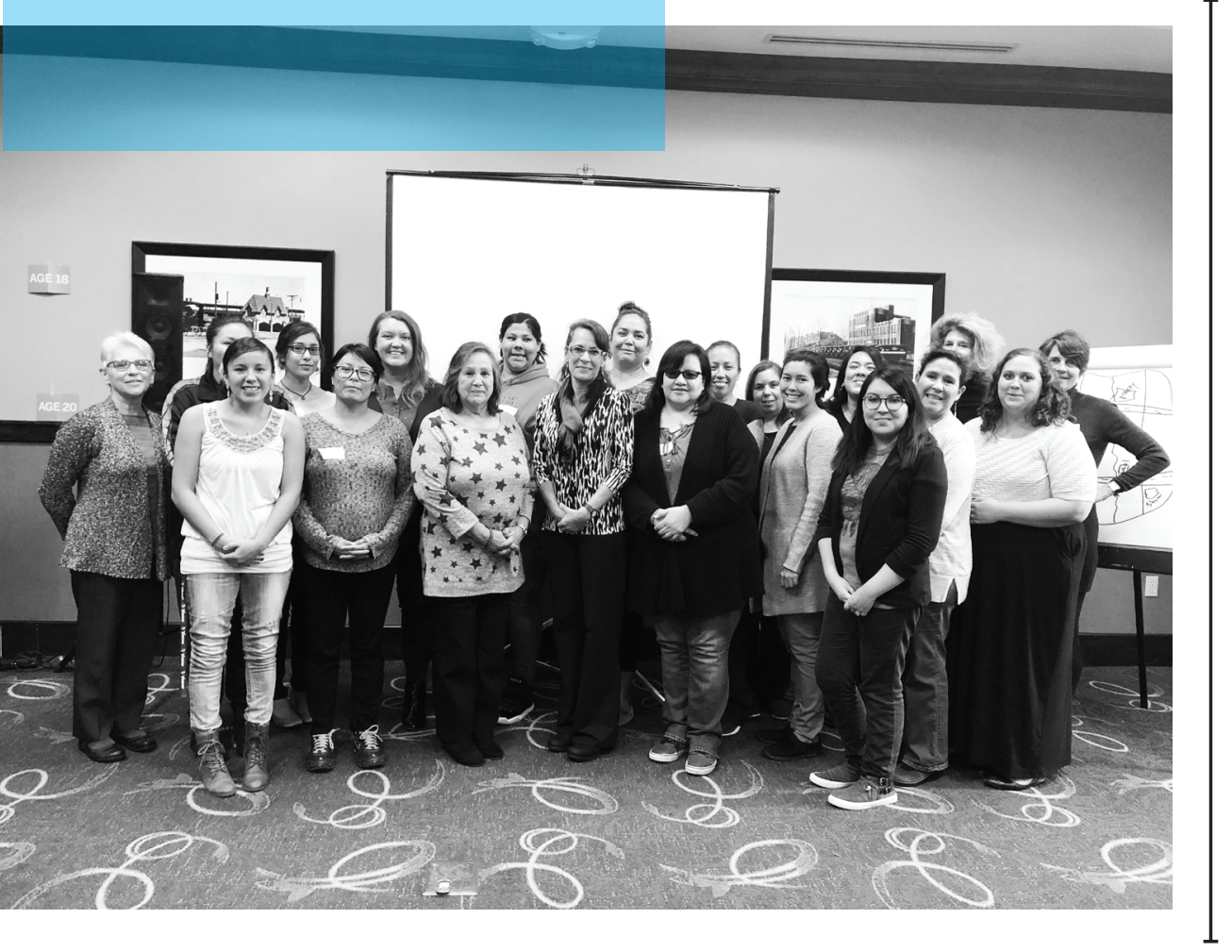

\section{MOVING FORWARD}

At the culmination of the workshop, participants who were interested in incorporating IMAGEN's model of girlcentered programming into their community work were invited to join the network and continue to be involved with upcoming events and initiatives, including the roll-out of IMAGEN's inaugural fellowship program in 2019. 


\section{Organizations represented by participants at the workshop:}

$>$ American Indian Science and Engineering Society

$>$ Hennepin County

$>$ IMAGEN Network

$>$ Kickapoo Tribe in Kansas

$>$ Little Wound BIA School

$>$ Lower Sioux Indian Community

$>$ Minneapolis Foundation, Catalyst Initiative

$>$ Minnesota State House of Representatives

$>$ Minnesota State Senate

$>$ Native Alliance Against Violence

$>$ White Buffalo Calf Women's Society

$>$ Wicincila Society

$>$ Women Win

\section{TO LEARN MORE}

about the network and how to bring girl-centered program

design to your indigenous community or organization, visit the IMAGEN website or contact us at:

\section{WWW.IMAGEN-NETWORK.ORG}

Dr. Kelly Hallman

khallman@popcouncil.org
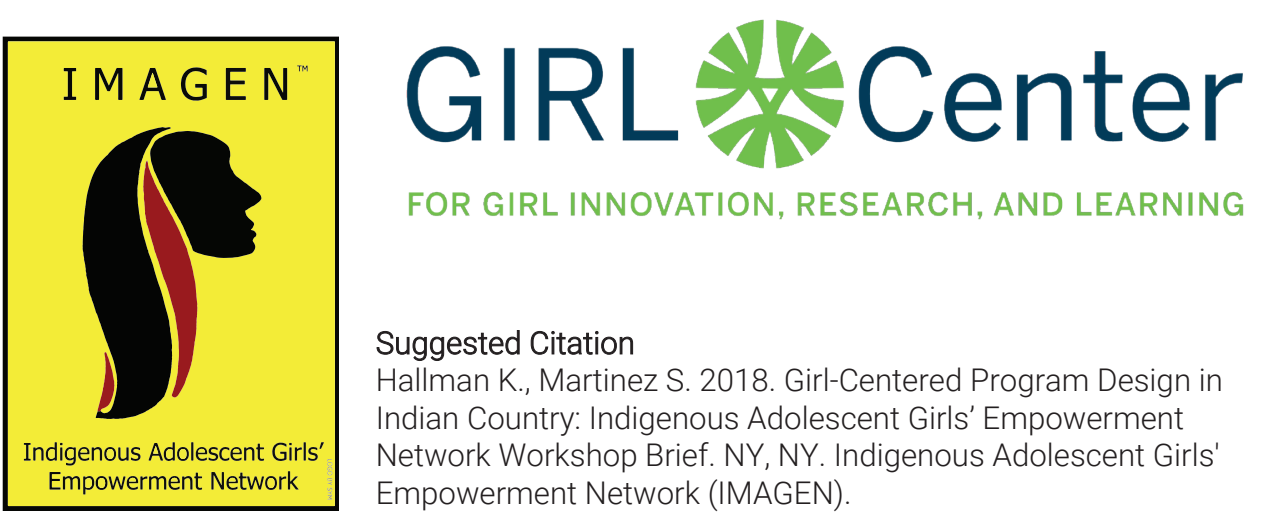

FOR GIRL INNOVATION, RESEARCH, AND LEARNING

\section{Suggested Citation}

Hallman K., Martinez S. 2018. Girl-Centered Program Design in Indian Country: Indigenous Adolescent Girls' Empowerment Network Workshop Brief. NY, NY. Indigenous Adolescent Girls' Empowerment Network (IMAGEN). 